\title{
FORMAÇÃO CONTINUADA DE PROFESSORES DE CIÊNCIAS: ELABORAÇÃO DE SITUAÇÕES-PROBLEMA
}

\author{
IN-SERVICE TRAINING IN SCIENCE \\ EDUCATION: DEVELOPING \\ PROBLEM-SOLVING SITUATIONS
}

RESUMO

Neste artigo apresentamos uma experiência didática desenvolvida em um curso de formação continuada de professores da Educação Básica. O objetivo foi fornecer ao professor da área de Ciências da Natureza subsídios teóricos e práticos para o trabalho com a metodologia da Resolução de Problemas. A abordagem está fundamentada em Larry Laudan, John Dewey e Jerome Bruner, de forma a discutir aspectos epistemológicos, pedagógicos e psicológicos da resolução de problemas. Os problemas produzidos pelos professores foram analisados conforme a área a que pertencem os conteúdos desenvolvidos e um conjunto de dicotomias relatadas na literatura. Os resultados obtidos na formação foram o aprofundamento do conhecimento teórico do professor da Educação Básica, a produção de material didático, a reflexão sobre a própria prática profissional e a utilização de metodologias alternativas de ensino.

Palavras-chave: Ensino de Ciências. Formação de professores. Metodologia de resolução de problemas.

\begin{abstract}
In this article we present a teacher training experience developed at an in-service training for Basic Education. The purpose was to provide the Science Education teachers with theoretical and practical background to work with Problem-Solving Methodology. The approach is based on the theories presented by Larry Laudan, John Dewey and Jerome Bruner, in order to discuss epistemological, pedagogical and psychological aspects of Problem-Solving. The problems developed by the participant teachers were analyzed according to their respective scientific areas, to the contents developed, as well as a set of dichotomies reported in the literature. The results of the training were the deepening of the theoretical knowledge of Basic Education teachers, the development of teaching material, the reflection on their professional practice, and the use of alternative teaching methodologies.
\end{abstract}

Keywords: Science Education. Teacher Training. Problem-Solving Methodology.

1 Professora da Universidade Federal do Pampa (UNIPAMPA), Brasil. Doutorado em Educação pela Universidade Federal do Rio Grande do Sul (UFRGS), Brasil. E-mail: maragoi@unipampa.edu.br

2 Professora da Universidade Federal do Rio Grande do Sul (UFRGS), Brasil. Doutorado em Educação pela Universidade Federal de Minas Gerais (UFMG), Brasil. E-mail: flavia.santos@ufrgs.br 


\section{Introduçáo}

O estudo é parte de um trabalho de doutoramento que acompanhou a trajetória de professores de Ciências da Natureza em um curso de extensão universitária. O objetivo das atividades desenvolvidas foi fornecer ao professor da Educação Básica subsídios para o trabalho com a metodologia de Resoluçáo de Problemas (RP), discutindo aspectos epistemológicos, pedagógicos e psicológicos da resolução de problemas. Para isso, foram aprofundados os estudos teóricos sobre Larry Laudan, John Dewey e Jerome Bruner, buscando fornecer aos professores formaçáo teórica e prática para o uso da metodologia em suas salas de aula. O objetivo da pesquisa relacionada foi investigar os aspectos necessários à formaçáo de professores aptos à utilização da metodologia em salas de aula da Educação Básica. Neste trabalho apresentamos os problemas ${ }^{3}$ produzidos pelos professores e realizamos uma análise aprofundada dos mesmos.

O curso de formação ocorreu na Universidade Federal do Rio Grande do Sul (UFRGS), durante os meses de setembro de 2013 a maio de 2014, teve duraçáo de 90 horas e contou com a participação de 24 professores da área de Ciências da Natureza. Como as atividades de extensão também compunham a realização de levantamento de dados para a pesquisa, os professores assinaram um Termo de Consentimento Livre e Esclarecido, autorizando que o material produzido durante a extensão fosse analisado para efeito de pesquisa, bem como divulgado academicamente.

Este trabalho permitiu aos professores o aprofundamento teórico em relaçáo aos aspectos trabalhados na elaboração de problemas, que passaram por diversas revisóes dos pares e da equipe de professores. Além disso, os professores foram incentivados a aplicar os problemas em suas aulas e discutir os resultados dessa implementação com seus colegas de formação. A formação foi realizada em três módulos, sendo que em um primeiro módulo trabalhou-se de forma intensiva os aspectos teóricos e a revisão da literatura sobre RP; em um segundo módulo, os professores elaboraram situaçóesproblema, e, em um terceiro módulo, aplicaram as situaçóes em suas aulas de ciências. Os resultados da implementação foram apresentados e discutidos no grupo de formação durante sessóes de socialização dos resultados. Neste artigo, apresentamos e analisamos os problemas produzidos no segundo módulo do curso de extensão universitária.

O objetivo do desenvolvimento de atividades da formação foi incentivar o professor da Educação Básica a aprofundar seu conhecimento teórico, a produzir seu próprio material didático, a fazer uma reflexâo sobre sua própria prática com outros professores e usar metodologias alternativas de ensino. Acreditamos que essa possa ser uma maneira de fazer com que os professores usem rotineiramente uma proposta de ensino que possibilita a construção do conhecimento científico e promove o desenvolvimento profissional dos professores que estão em formação e o desenvolvimento cognitivo dos alunos usuários dessa metodologia em aula.

As atividades visam o estabelecimento de uma base conceitual a partir da qual ocorre o aprofundamento e a contextualizaçáo. Isso ocorreu quando os exemplares dos problemas foram apresentados para os professores e, a partir daí, eles elaboraram os seus problemas que foram discutidos, negociados e reformulados no grupo de formaçáo.

O curso de formação permitiu que o professor refletisse sobre as suas dificuldades conceituais, pedagógicas, epistemologias para a produção de situaçóes de ensino-aprendizagem.

Os sujeitos dessa experiência foram, na maioria, professores de escolas públicas da Grande Porto Alegre - RS, que lecionam no Ensino Fundamental II, no Ensino Médio e EJA, formados em Ciências da Natureza (Física, Química e Biologia). Alguns desses sujeitos têm formação em outras áreas do 
conhecimento, a saber: Bacharel em Química, Engenharia Química, Bacharel em Biologia e Química Industrial. Ao longo da ação de extensão, o número de professores envolvidos na formaçáo foi se modificando. Por ser um curso ofertado aos sábados e ter uma carga horária de média duração ( 90 horas), muitos professores desistiram de frequentar o curso devido às demandas profissionais enfrentadas em sua jornada diária, como justificado pelos desistentes. Dos 24 professores matriculados e frequentes até a metade do curso, 18 finalizaram a extensão obtendo o mínimo de $75 \%$ de frequência.

Todos os professores que compóem a amostra fizeram (ou fazem) o curso de graduação na modalidade presencial e a maioria graduou-se em instituição privada de ensino.

\section{Resoluçáo de problemas no Ensino de Ciências: fundamentos teóricos}

Com o objetivo de superar o modelo de treinamento utilizado em muitos cursos de formação, a implementação, descrita neste trabalho, buscou a abordagem conceitual e de fundamentação dos aspectos envolvidos na elaboração dos problemas e na definição da estratégia metodológica coerente com o ensino e a aprendizagem de Ciências. Acreditamos que, quando o professor estiver inserido em um processo de vivência e estudo da estratégia de RP, ele desenvolverá a habilidade de resolver situaçóes e poderá aplicar essa metodologia em seu contexto de sala de aula. Contudo, esta habilidade não é desenvolvida apenas pelo uso de técnicas de elaborar e resolver situaçóes-problemas, mas pelo estudo aprofundado de referenciais teóricos, pelo processo de elaborar problemas, pela aplicaçáo da metodologia nos contextos de salas de aula e pelo uso rotineiro da estratégia.

$\mathrm{Na}$ abordagem adotada, a fundamentaçấo epistemológica foi obtida a partir do trabalho de Larry Laudan $(1977,1990)$. A perspectiva de que a ciência é, em essência, uma atividade de RP, ancora a tese de que a ciência deve ser ensinada a partir dessa atividade e que nela estâo imbricadas a história e a filosofia da Ciência, que deveriam compor os programas de formaçáo de professores e o cotidiano das salas de aulas (MATTHEWS, 2009). Laudan (1977) considera que nem os filósofos, nem os historiadores da ciência têm dedicado tempo e atenção suficientes para a adequada compreensão do que é conceber a ciência como uma atividade de RP. Essa atividade gera, segundo o autor, um progresso cognitivo que se relaciona às aspiraçóes intelectuais da ciência. A Ciência progride pela maneira como resolve, adequadamente ou não, uma série de problemas gerados no meio social.

Laudan (1977) descreve aspectos importantes relacionados à epistemologia da RP. Esboçou um modelo de racionalidade cujo fundamento é a noção de progresso, e também sugeriu que as unidades de análise não deveriam ser as teorias em si, mas o que ele denominou de tradição de investigação. $\mathrm{O}$ autor estabelece duas teses quando discute o papel das teorias como soluçôes de problema. A primeira refere-se à teoria oferecer perguntas interessantes e respostas aceitáveis, em outras palavras, oferecer soluçöes satisfatórias a problemas importantes (1977, p. 13). O autor argumenta que, embora isso pareça indiscutível, não há bibliografia e metodologia que ofereçam uma taxonomia adequada sobre os tipos de problemas científicos, como também um método aceitável para avaliar a importância dos problemas para o desenvolvimento da ciência. Assim, 
há um silêncio acerca dos critérios adequados para resolver as situaçóes. A filosofia da ciência não reconhece diferentes graus de dificuldade para resolver diferentes problemas, por isso concebe todas as situaçôes em nível de igualdade, e não que algumas soluçôes são melhores e mais aceitáveis que outras.

Para a construção da argumentação e compreensão da relevância da RP, Laudan (1977, p.14) propóe a segunda tese: ao avaliar os méritos das teorias é mais importante perguntar se constituem soluçôes adequadas a problemas significativos, que perguntar se säo "verdadeiras", "corroboradas", "bem confirmadas" ou justificáveis de outra maneira dentro do quadro conceitual da epistemologia contemporânea. Em relação a esta segunda tese, podemos verificar que Laudan acredita em um contraponto entre problemas instigantes e teorias adequadas, a isso ele chama de dialética básica da ciência. Deve-se ter mais clareza sobre o que são os problemas e como funcionam, como também sobre a natureza das teorias e de suas relaçôes com os problemas que as geram.

Para desenvolver as teses, o autor inicialmente elabora uma taxonomia dos problemas, caracteriza e diferencia teoria e problema e estabelece as bases para uma análise epistemológica construída sobre tradiçôes de investigaçôes. Para ele, os problemas sáo classificados em dois grupos, problemas empíricos e conceituais, e é através deles que a ciência progride. Os problemas empíricos são qualquer coisa do mundo natural que nos surpreende, algo estranho que necessita de uma explicaçáo. São problemas de primeira ordem, perguntas acerca dos objetos que constituem o domínio de determinada ciência. Os problemas empíricos são situaçóes que surgem em certos contextos de investigaçáo teórica, admitindo que sua formulação seja influenciada por nossos compromissos teóricos e que estes são problemas acerca do mundo.

Quanto aos problemas conceituais, Laudan afirma que estes podem ser diferenciados em problemas conceituais internos e externos. Os problemas conceituais internos surgem com o descobrimento de que uma teoria é logicamente inconsistente e autocontraditória. Há uma segunda classe de problemas conceituais internos que surgem de uma ambiguidade ou circularidade conceitual de uma teoria. Pode-se dizer que esses dois tipos de problemas são peças importantes no processo de "validação" de uma teoria. Uma teoria gera problemas conceituais externos quando está em conflito com outra teoria ou doutrina que seus "partidários" creem que está bem fundada. A existência deste conflito ou tensáo constitui o que se pode chamar de problema conceitual. Os problemas conceituais nem sempre são gerados pela mera incompatibilidade entre teorias. Ao se tratar de problemas conceituais externos, é preciso compreender que tipos de teorias ou crenças podem gerar problemas conceituais para uma teoria científica.

Como elementos centrais e conclusivos de seu modelo, Laudan (1977, p. 66) estabelece que a soluçáo de problemas empíricos e conceituais é a base fundamental do progresso científico. O objetivo da ciência é maximizar o escopo de problemas empíricos resolvidos, assim como maximizar o escopo dos problemas anômalos e conceituais. Isso significa que, quanto mais numerosos e difíceis são os problemas que uma teoria resolve, mais adequada ela se torna.

Quanto ao aspecto pedagógico da resolução de problemas, trabalhamos os referenciais de John Dewey (2010), que defendia a democracia no campo institucional e no interior das escolas. No campo educacional, ficou conhecido por acreditar que os estudantes aprendem realizando tarefas associadas aos conteúdos ensinados. Valorizou a 
expressão "experiência", por acreditar que o professor deve valorizar a experiência de cada aluno. Para o autor, a 'experiência' pode ser compreendida se levarmos em conta dois elementos antagônicos: um deles está relacionado à experiência como tentativa, e o outro, como sofrimento. A simples atividade não se constitui como experiência; é dispersiva, centrífuga e dissipadora.

A experiência é entendida como mudança quando for refletida, pensada e analisada. Para Dewey (2010), tudo depende da qualidade da experiência e toda a experiência vive e se perpetua nas experiências que a sucedem, logo, uma educaçáo baseada na experiência deverá ser frutífera e criativa nas experiências subsequentes. Nessa visão, uma experiência é o fruto da interação entre o indivíduo e o ambiente. A experiência deve ser vista como crescimento, ela é um continuum. Uma escola com base na experiência de vida de cada estudante seria, na opiniáo de Dewey (2010), um espaço que prioriza a individualidade, partindo da sua própria experiência, cujas características são variáveis em cada indivíduo.

Nesta perspectiva, torna-se importante trabalharmos com propostas alternativas de ensino que promovam a capacidade de argumentação e que valorizem a experiência de cada indivíduo, inserindo-o no contexto escolar, e, desta forma, a RP se constitui como uma alternativa pedagógica adequada.

Quanto aos aspectos psicológicos, utilizamos os referenciais de Jerome Bruner e o conceito de desenvolvimento intelectual. Para o autor, o ensinar é um esforço para moldar o desenvolvimento, e muito do desenvolvimento intelectual começa quando nos voltamos sobre nossos próprios passos e passamos a modificá-los, com a ajuda de professores, indo, entấo, a outros modos de organizaçáo. É por isso que o processo educativo consiste em fornecer auxílio e diálogo para traduzir a experiência em sistemas mais poderosos de notação e ordenação (BRUNER, 1969, p.35).

Bruner (2008, p.88) distingue dois tipos de ensinar: um está relacionado ao modelo expositivo e o outro a um modelo hipotético. $\mathrm{O}$ modelo expositivo trata o professor como expositor e o estudante como ouvinte. $\mathrm{O}$ professor tem o poder de decisóes, enquanto que o aluno não tem discernimento das opçôes internas. No modelo hipotético, o professor e o estudante estáo em uma posição de cooperação, o que, em linguística, denomina-se "decisões do orador". Neste modelo, o estudante toma parte das formulaçóes, fica ciente das alternativas e tem liberdade de expressão. Para o autor, o modo hipotético caracteriza o ato de ensinar, o que leva ao encorajamento da descoberta. Esta, por sua vez, possibilita ao aluno pesquisar, resolver situaçóes não rotineiras em sala de aula e isso conduz à a elevação do potencial intelectual e o processo de conservação da memória (BRUNER, 2008, p.89).

$\mathrm{O}$ potencial intelectual é evidenciado através da RP e das iniciativas à pesquisa. $\mathrm{O}$ indivíduo que pesquisa, que encontra regularidades e relaçóes na solução de um problema, precisa estar com expectativa de que há algo para ser descoberto. Nesse sentido, o potencial intelectual deve ser marcado por transformar o que foi descrito em uma hipótese, bem como enfatizar a descoberta, levando a criança a aprender uma variedade de formas para resolver problemas e transformar a informação para ser melhor utilizada. Isto, na concepção do autor, significa aprender como lidar com a tarefa de aprender.

Portanto, Bruner defende um ensino voltado à descoberta e à resoluçáo de problemas. A descoberta que o autor propóe é sinônimo de pesquisa e náo aquela 
interpretação de muitos pesquisadores da área de ciências dos anos 70, que concebiam o ensino de ciências como um ensino voltado à redescoberta. Segundo esse modelo, os alunos aprendem qualquer conteúdo científico por conta própria, a partir da observação e de trabalhos "experimentais".

O ensino por redescoberta foi um assunto polêmico na área de Ciências na década de 90. Uma polêmica de natureza filosófica refere-se ao indutivismo extremo, inerente ao uso tradicional do laboratório, que privilegia observações e experimentaçôes livres e que, por isso, desconsidera o papel essencial da construção de hipóteses e de um corpo coerente de conhecimento (GIL-PÉREZ, 1996). Essa polêmica fomenta o debate referente às atividades que se propóem apenas a testar fenômenos cujos resultados já são conhecidos e esperados, muito característicos do ensino tradicional e das aulas por redescoberta. A descoberta, na teoria de Bruner, deve ser entendida como uma atividade de investigaçáo, pesquisa e resolução de situaçóes-problema.

\section{Problemas construídos no curso de formaçáo}

Apresentamos exemplares dos problemas elaborados pelos professores em formação durante o segundo módulo da extensão e os analisamos conforme as categorias descritas na literatura. Para a preservação da identidade pessoal e profissional, os docentes foram, então, denominados pela letra $\mathrm{D}$ seguida da sequência numérica do 1 ao 18 . Os problemas estão organizados em blocos e em ordem alfabética, seguindo uma sequência numérica. Os problemas estáo apresentados em seu formato original, conforme proposto pelos professores em curso de formação, sem alteraçóes semânticas, sintáticas ou gramaticais. Outro aspecto a ser considerado está relacionado à autoria dos problemas: alguns professores preferiram construí-los em pares, outros em grupos e poucos optaram por fazê-lo individualmente. Os problemas que foram elaborados pelos professores estão apresentados a seguir, no Quadro 1.

\section{Quadro 1- Problemas produzidos pelos professores em curso de formaçáo}

continua

\begin{tabular}{|l|l|}
\hline Docentes & Bloco de problemas \\
\hline \multirow{1}{*}{ D1 e D2 } & $\begin{array}{l}\text { Bloco A } \\
\text { P1- O desenvolvimento tecnológico traz embutidas diversas consequências danosas. O homem cria } \\
\text { inúmeras formas e alternativas de buscar resultados mais eficientes a menores custos. Muitas vezes não } \\
\text { dimensiona o resultado de suas atitudes e não tem uma visão global do mundo em função dos prós e } \\
\text { contras, problema que causa, direta ou indiretamente, danos ao meio ambiente. O que você entende por } \\
\text { 'Problema Ambiental'? Quais as principais causas? } \\
\text { P2- Os problemas ambientais estão cada vez mais se amplificando e se tornando rotineiros em nossas vidas. } \\
\text { Muitas indústrias não tratam seus resíduos e despejam em rios produtos químicos, causando poluição e } \\
\text { mortandade de peixes. As pessoas sujam as ruas, o que provoca o entupimento de bueiros, resultando } \\
\text { em alagamentos, quando chove. Essa situação pode provocar problemas no transporte e doenças como a } \\
\text { leptospirose, além de outros. Escolha } 1 \text { (um) problema ambiental da sua cidade e especule sobre o que } \\
\text { pode ter ocasionado. Relacione a Química com esse problema. } \\
\text { P3 - A solução para os problemas ambientais está em promover uma melhor organização da cidade e } \\
\text { também na informação e educação ambiental para a população, promovendo a integração da comunidade } \\
\text { em busca de melhores condições junto às autoridades para solucionar os problemas da mesma. } \\
\text { Que soluções você propõe para resolver ou minimizar o problema ambiental da sua cidade? }\end{array}$ \\
\hline
\end{tabular}




\begin{tabular}{|c|c|}
\hline Docentes & Bloco de problemas \\
\hline D3 e D4 & $\begin{array}{l}\text { Bloco B } \\
\text { P4 - A ciência que estuda as interações dos seres vivos entre si e com o ambiente é chamada de Ecologia. } \\
\text { Para compreendermos melhor o estudo da Ecologia, temos alguns conceitos muito importantes, um deles é } \\
\text { ECOSSISTEMA. Ecossistema é o conjunto formado pelos seres vivos e o ambiente em que eles vivem, incluindo } \\
\text { suas relações. Os ecossistemas apresentam características próprias, diferenciando-se quanto aos fatores } \\
\text { ambientais e aos seres vivos existentes no local. Sabendo disso, através de estudo de campo, podemos } \\
\text { entender, na prática, como funciona um ecossistema. Se você analisar algum ambiente natural, é possível } \\
\text { relacionar com um ecossistema? Observe detalhadamente um ambiente natural próximo de sua casa e } \\
\text { descreva-o. Que tipo de ecossistema foi encontrado? } \\
\text { P5- Os fungos são seres heterótrofos, ou seja, incapazes de produzir seu próprio alimento. Nos fungos a digestão é } \\
\text { extracorpórea, ou seja, é realizada fora do corpo. O fungo lança no ambiente enzimas que degradam as moléculas } \\
\text { orgânicas complexas e depois, absorve moléculas menores, mais simples. A principal atividade dos fungos é a } \\
\text { decomposição da matéria orgânica, de extrema importância para manutenção dos ecossistemas. } \\
\text { Imagine-se como um cientista e demonstre, através de um experimento, o surgimento de fungos em } \\
\text { seu dia a dia. Observe seu experimento todos os dias, fotografe, faça suas anotações e conclua. Quais as } \\
\text { condições ideais para o desenvolvimento dos fungos? O que aconteceria se os fungos fossem extintos? }\end{array}$ \\
\hline D5 & $\begin{array}{l}\text { Bloco C } \\
\text { P6 - No rótulo de algumas margarinas observamos a expressão: } 0 \% \text { de gordura trans. Do ponto de vista } \\
\text { da química, como é caracterizada uma gordura trans e quais os efeitos do consumo desse tipo de } \\
\text { gordura em nosso organismo? } \\
\text { P7 - Você já deve ter observado, em algumas marcas de margarina vendidas em supermercados, a seguinte } \\
\text { indicação: rica em poli-insaturados. Apesar de as moléculas das gorduras vegetais que entram na composição } \\
\text { dessas margarinas pertencerem à outra função orgânica, suas longas cadeias carbônicas contêm mais de } \\
\text { uma insaturação, daí a denominação poli-insaturados. Esta mesma indicação não é encontrada em rótulos } \\
\text { de manteiga. Pesquise a diferença química entre margarina e manteiga, mostrando qual é a mais } \\
\text { saudável para nosso consumo e proponha um experimento para identificar essa diferença. }\end{array}$ \\
\hline
\end{tabular}

\section{Bloco D}

P8 - A alguns meses de um dos maiores eventos esportivos mundiais, as lesões esportivas voltam a preocupar os técnicos de futebol. Atualmente, a maior parte das lesões não está relacionada a pancadas, mas sim a movimentos de rotação e explosão muscular. Em uma análise dos prontuários médicos de oito times profissionais, ortopedistas da Universidade Federal de São Paulo (Unifesp) constataram que as lesões por choque entre jogadores (as chamadas contusões) representaram apenas $24,1 \%$, contra $39,2 \%$ de lesões musculares, $17,9 \%$ de torções e $13,4 \%$ de tendinites. Além disso, o estudo apontou que $72,2 \%$ das lesões ocorreram em membros inferiores, com predomínio na coxa $(34,5 \%)$, no tornozelo $(17,6 \%)$ e no joelho (11,8\%). "A cada 6 segundos o jogador de futebol faz um movimento inesperado. Articulações e músculos foram feitos para mexer, mas o ser humano ultrapassa os limites de movimentação do seu corpo e aí ocorrem as lesões", diz o ortopedista Moisés Cohen, que coordenou o levantamento da Unifesp e já operou craques como Raí e Vampeta. Um estudo dos médicos ingleses Richard Hawkins e Colin Fuller, publicado no British Journal of Sports Medicine, mostrou que $71 \%$ das lesões ocorridas na Copa do Mundo de 1994 aconteceram em lances não assinalados como faltas, o que indica que o maior inimigo do atleta é a competitividade do futebol moderno. "O movimento não precisa ser brusco para machucar. Muitos rompem o ligamento cruzado (do joelho), por exemplo, por causa de um movimento sozinho", conclui Moisés Cohen. As lesões musculares resultam do agrupamento de diferentes tecidos que interagem durante um trauma. Pesquise quais são os tipos de tecidos humanos e suas funções.

P9 - A sigla FPS, que aparece nas embalagens de protetores solares, quer dizer Fator de Proteção Solar. Vem acompanhada de um número que indica o grau de proteção do produto e é um dos vários procedimentos destinados à proteção de qual tecido? Baseado na teoria que você pesquisou, procure representar o tecido

D6, D7, D8 $\begin{aligned} & \text { estudado. Você pode usar quaisquer materiais para fazê-lo. } \\ & \text { P10 - Paulo dançando Hip Hop, em uma manobra radical, bateu no chão e acabou fraturando a perna. O que ocorreu }\end{aligned}$ com o tecido ósseo? Baseado na teoria que você pesquisou, procure representar o tecido estudado. Você pode usar quaisquer materiais para fazê-lo.

P11 - Juninho jogou futebol na aula de educação física. Após a aula, sentiu fortes dores na panturrilha, devido a uma câimbra. O que ocasionou essa câimbra? Como Juninho poderia ter evitado esse fato? Baseado na teoria que você pesquisou, procure representar o tecido estudado. Você pode usar quaisquer materiais para fazê-lo.

P12 - Em busca de um corpo perfeito, cada vez mais, mulheres e homens estão recorrendo à lipoaspiração. Esse procedimento consta na retirada de gordura através de cânulas da região desejada. Baseado na teoria que você pesquisou, procure representar o tecido estudado. Você pode usar quaisquer materiais para fazê-lo.

P13 - Enquanto Ana descascava batatas, cortou a sua mão com uma faca. Logo, Ana percebeu que o sangramento parou.

Como ocorreu esse fato? Baseado na teoria que você pesquisou, procure representar o tecido estudado. Você pode usar quaisquer materiais para fazê-lo.

P14 - Hoje em dia várias pessoas estão adornando seus corpos com piercings. Os mesmos são colocados nos mais variados locais: sobrancelha, face, língua, umbigo, orelha, nariz, entre outros. Em alguns casos, cria-se uma protuberância chamada queloide na cartilagem. Como isso ocorre? Baseado na teoria que você pesquisou, procure representar o tecido estudado. Você pode usar quaisquer materiais para fazê-lo.

P15 - Os tecidos estudados nos levaram a um vasto conhecimento macro e microscópico do corpo humano. Porém, nem sempre essa máquina humana é perfeita.

De acordo com o tipo de tecido estudado anteriormente, busque informações sobre as doenças (sintomas, tratamento e prevenção) que podem acometer o tecido. 


\begin{tabular}{|c|c|}
\hline Docentes & Bloco de problemas \\
\hline D9 & $\begin{array}{l}\text { Bloco E } \\
\text { P16 - Verificou-se que os impactos ambientais, termo bastante utilizado atualmente, podem ser ocasionados } \\
\text { de várias maneiras e atividades. Nota-se que os mesmos sempre existiram, naturalmente ou não. Obviamente } \\
\text { que o impacto humano sobre o ambiente até os dias de hoje constitui-se em uma parcela muito } \\
\text { maior, quando comparada aos impactos naturais. Diante disto, pesquise sobre os tipos de problemas } \\
\text { ambientais existentes no País que sua turma está trabalhando. } \\
\text { P17 - O homem necessita rever seu modo de vida, fazer novas escolhas, que contribuam para a redução do } \\
\text { impacto humano individual e social no planeta. Pensando nisso, como a cultura interfere nestas questões? } \\
\text { P18 - Que tipo de atitudes o homem pode ter para diminuir esses impactos e amenizar os problemas } \\
\text { gerados no convívio ambiental? }\end{array}$ \\
\hline D10 & 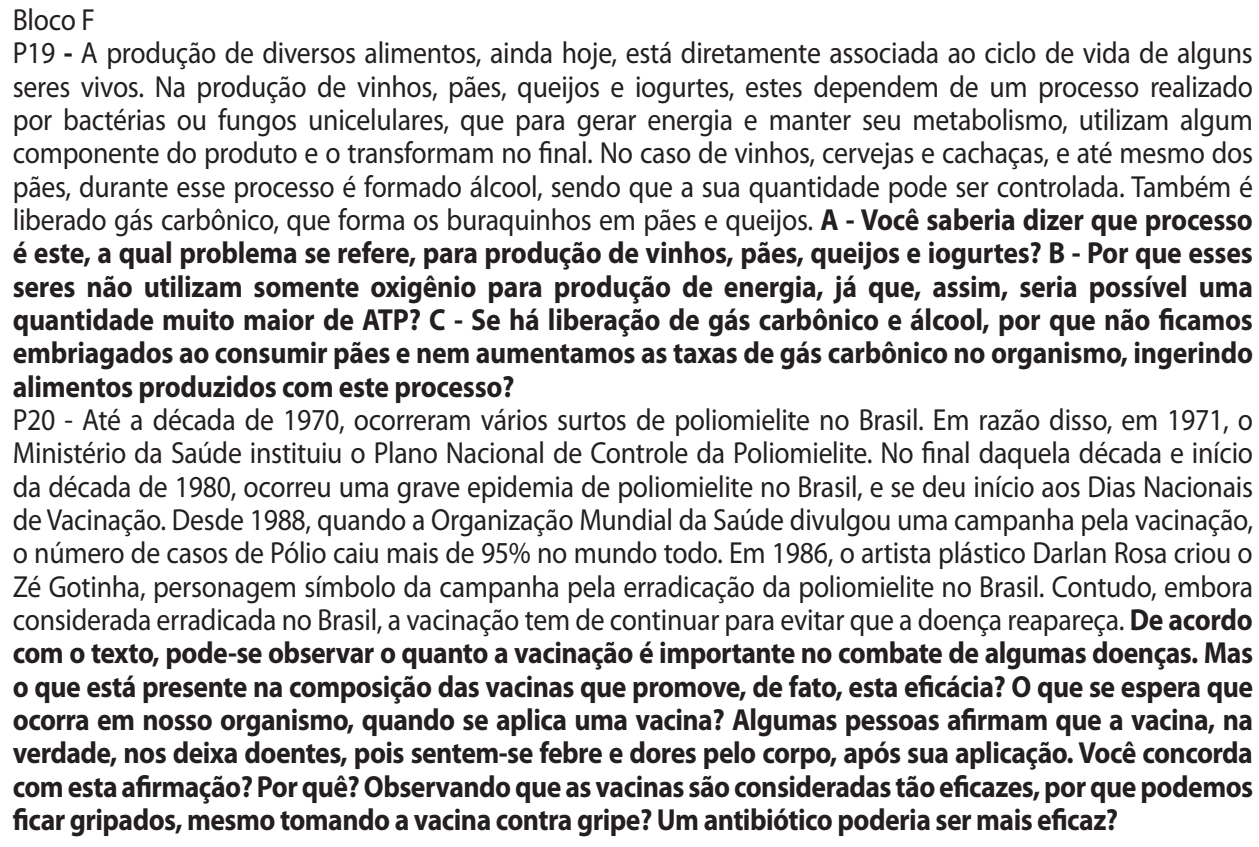 \\
\hline D11 & $\begin{array}{l}\text { Bloco G } \\
\text { P21 - Na natureza, é raro encontrarmos substâncias puras, normalmente encontramos misturas de substâncias, } \\
\text { e muitas vezes essas misturas não possuem grandes utilidades. A água do mar é um exemplo de uma mistura } \\
\text { de água com vários sais dissolvidos que não possui muita serventia, entretanto, se evaporarmos a água, nós } \\
\text { obtemos o sal, com grande utilidade no nosso dia a dia. Imagine uma pessoa que não tem acesso à água do } \\
\text { mar, mas consegue uma grande quantidade de uma mistura de areia e sal. Explique como essa pessoa pode } \\
\text { obter sal puro a partir dessa mistura, identificando os processos e materiais utilizados. } \\
\text { P22 - A água é um recurso renovável pelo ciclo natural evaporação - chuva e distribuída com fartura na maior } \\
\text { parte da superfície do planeta. Acontece que a ação humana afetou de forma decisiva a renovação natural } \\
\text { dos recursos hídricos. Estima-se que } 50 \% \text { dos rios do mundo estejam poluídos por esgotos, dejetos industriais } \\
\text { e agrotóxicos. Para que tenhamos água potável para consumirmos, ela passa por tratamento. Pesquise as } \\
\text { etapas do tratamento da água e diga quais são métodos de separação de misturas, justificando. }\end{array}$ \\
\hline D12 e 13 & $\begin{array}{l}\text { Bloco H } \\
\text { P23 - Na Copa do Mundo de } 2014 \text { no Brasil, a FIFA tem uma missão clara: manter o futebol livre do dopping. Para } \\
\text { isso, a FIFA anunciou no dia } 1^{\circ} \text { de março, em São Paulo, que todos os jogadores que irão disputar a Copa do } \\
\text { Mundo deste ano serão submetidos em algum momento a um teste antidopping surpresa. O antidopping é } \\
\text { um exame realizado para saber se o atleta ingeriu alguma substância proibida. Os testes serão realizados com } \\
\text { amostra da urina ou sangue. Existem alguns tipos de substâncias proibidas, como os estimulantes, calmantes, } \\
\text { diuréticos, esteroides e anabolizantes, que mesmo em pequena quantidade, podem dar vantagem ao atleta } \\
\text { numa competição, aumentando o desempenho esportivo. Outra forma de melhorar o rendimento dos atletas é } \\
\text { o dopping sanguíneo. A) Pesquise no que consiste este procedimento, quais as vantagens que o competidor } \\
\text { espera obter e qual sua relação com os processos de metabolismo celular (respiração e fermentação). } \\
\text { Represente as principais reações envolvidas na glicólise, etapa comum aos dois processos, e explique o } \\
\text { que ocorre na ausência de oxigênio na célula muscular. B) Caso o competidor morasse ou treinasse por } \\
\text { várias semanas em região montanhosa de elevada altitude para participar de um campeonato em uma } \\
\text { cidade localizada no nível do mar, qual seria o resultado obtido? Discuta a questão ética envolvida nessas } \\
\text { duas situações e por que somente o dopping sanguíneo é considerado ilegal. }\end{array}$ \\
\hline
\end{tabular}




\begin{tabular}{|c|c|}
\hline Docentes & Bloco de problemas \\
\hline $\mathrm{D} 12 \mathrm{e} 13$ & 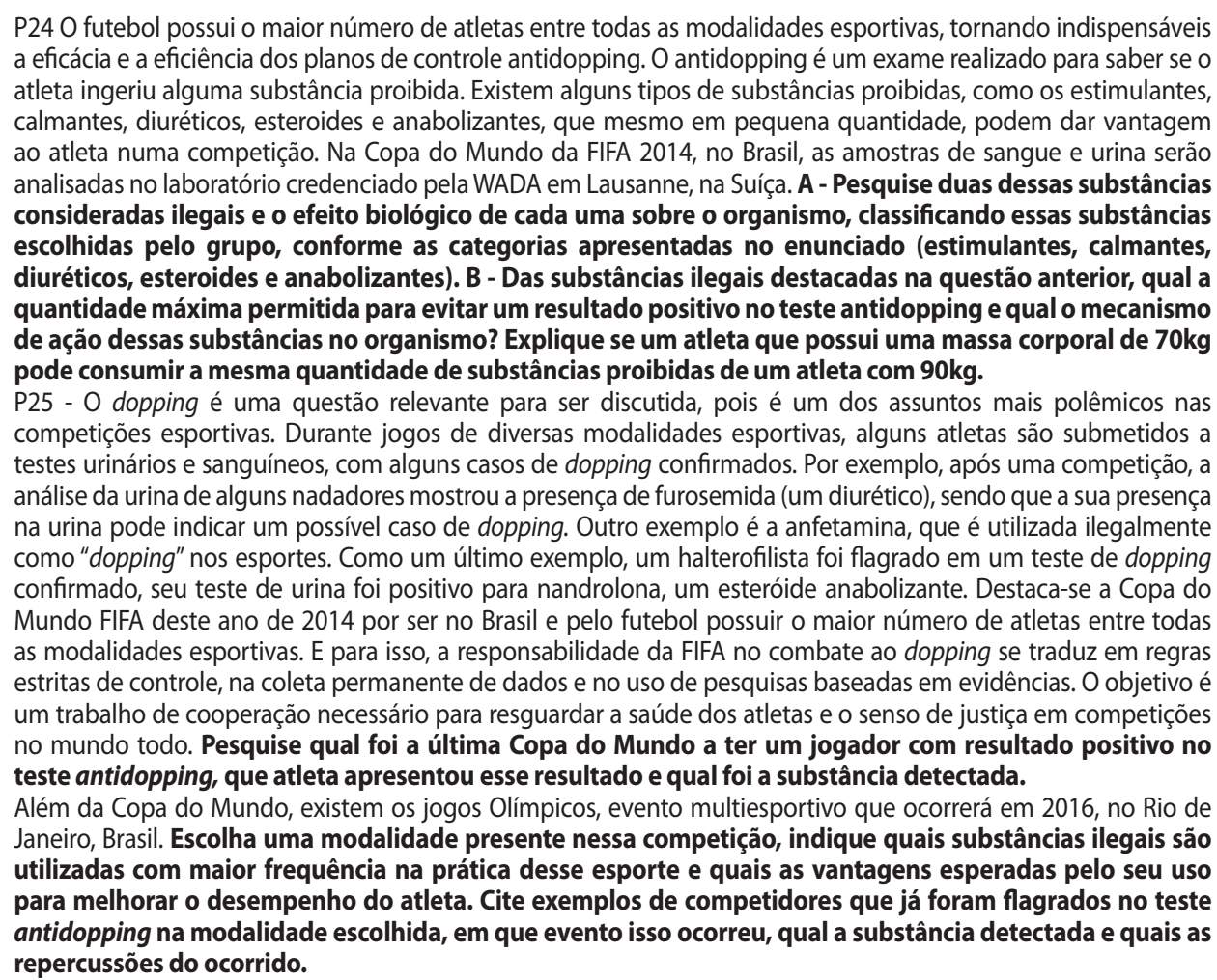 \\
\hline D14 & $\begin{array}{l}\text { Bloco I } \\
\text { P26 - Após a queda do homem em pecado, Deus fala a Adão e Eva: "Por causa do que você fez, a terra será maldita. } \\
\text { Você terá de trabalhar duramente a vida inteira a fim de que a terra produza alimento suficiente para você (...). } \\
\text { Isto até que você volte à terra, pois dela você foi formado. Você foi feito de terra e vai virar terra outra vez". Gênesis } \\
\text { 2.17-19. A vida do ser humano e sua relação com o meio ambiente sofreu graves consequências após a queda } \\
\text { em pecado. Uma dessas consequências foi a tarefa de cultivar a terra para obter alimento. Qual a origem dos } \\
\text { alimentos consumidos pelos seres humanos? Como são classificados? } \\
\text { P27 - No relato de Gênesis, podemos observar que a família de Adão e Eva, provavelmente, consumia alimentos } \\
\text { de origem animal e vegetal. Seus filhos trabalhavam em diferentes tipos de atividades: Caim era agricultor e Abel } \\
\text { era pastor de ovelhas. Você já deve ter ouvido alguém falar que é importante "comer de tudo um pouco", e que } \\
\text { alguns tipos de alimentos são muito importantes para crianças e adultos. O que é uma alimentação saudável? } \\
\text { Organize, em sala de aula, uma apresentação sobre o assunto. } \\
\text { P28 - O ser humano é capaz de perceber sabores e odores diferentes nos alimentos. A estes sentidos chamamos } \\
\text { de"paladar" (sentir o gosto) e"olfato" (sentir o cheiro), esses são muito importantes na hora de escolhermos o que } \\
\text { vamos comer. Proponha um experimento para demonstrar a nossa percepção dos sabores ou odores dos } \\
\text { alimentos. }\end{array}$ \\
\hline $\mathrm{D} 15,16$ & $\begin{array}{l}\text { Bloco J } \\
\text { P29 - As drogas estão classificadas em lícitas, liberadas em seu uso por lei, e ilícitas, não liberadas. As } \\
\text { lícitas têm como exemplo o álcool, que é utilizado em "massa" por adolescentes, muitas vezes menores de } \\
\text { idade, em reuniões de amigos e festas. Segundo lçami Tiba (2007), os adolescentes que fazem uso abusivo } \\
\text { de álcool acabam, muitas vezes, por experimentar maconha, abrindo as "portas" para as drogas ilícitas. } 0 \\
\text { que motiva os adolescentes de } \mathbf{1 5} \text { a } \mathbf{1 8} \text { anos a usarem drogas? E na sua cidade, quais as drogas mais } \\
\text { utilizadas entre os jovens? } \\
\text { P30 - Quando fazemos uso de drogas, liberamos no organismo diferentes neurotransmissores que agem } \\
\text { no SNC (Sistema Nervoso Central), modificando o comportamento de quem as usa. Como essas drogas } \\
\text { podem liberar no SNC substâncias químicas produzidas por neurônios? Usando como parâmetro as } \\
\text { drogas pesquisadas no problema anterior, quais os neurotransmissores liberados por elas, durante o } \\
\text { uso, e como agem no SNC? } \\
\text { P31- Do ponto de vista químico, podemos classificar as substâncias orgânicas levando em consideração os } \\
\text { grupos funcionais presentes na sua molécula. As drogas e os neurotransmissores são compostos orgânicos } \\
\text { formados por variadas funções. Nas drogas do PI, quais as funções que estão presentes? Estas funções } \\
\text { influenciam a ação destas drogas no organismo? De qual forma? }\end{array}$ \\
\hline
\end{tabular}




\begin{tabular}{|c|c|}
\hline Docentes & Bloco de problemas \\
\hline D17,18 & 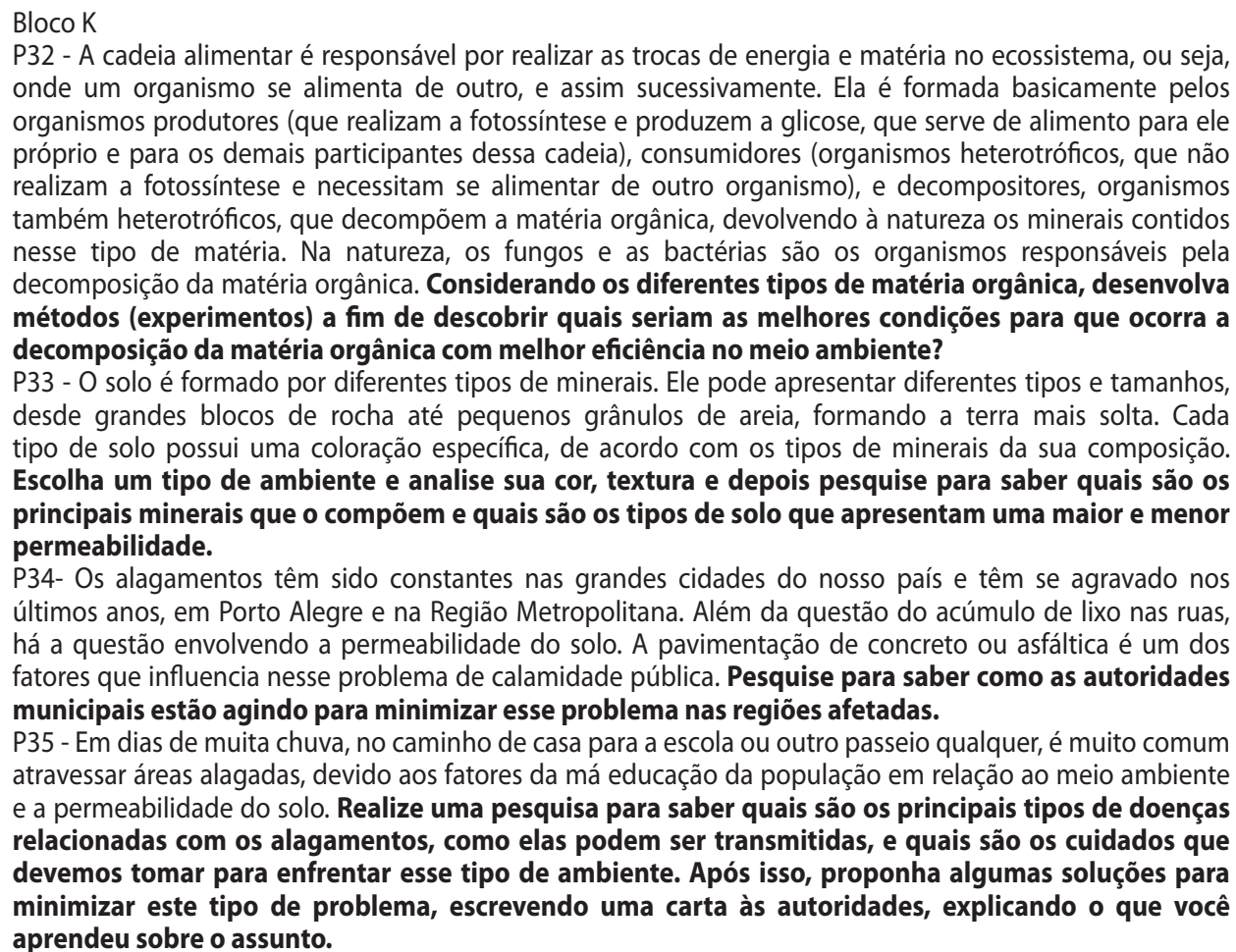 \\
\hline
\end{tabular}

\section{Análise dos problemas elaborados}

A partir da análise desses problemas, podemos classificá-los conforme a área a que pertencem, ao conteúdo desenvolvido em cada situação-problema e as dicotomias definidas na literatura específica: problemas dedutivos ou indutivos; definidos ou indefinidos; escolares, científicos ou problemas do cotidiano; abertos ou fechados, formais ou informais; curriculares ou não curriculares, livres ou orientados, dados ou apropriados, reais ou artificiais e sobre a natureza de cada situação-problema, natureza teórica, experimental ou teórica-e-experimental. (ECHEVERRIA; POZO, 1998; POZO; CRESPO, 1998; WATTS, 1991).

Das 35 situaçóes produzidas, seis são tratadas de forma interdisciplinar entre as disciplinas de Química e Biologia (P23, P24, P25) e Biologia e Ensino Religioso (P26, P27, P28). As demais foram incluídas nas áreas de Ciências Biológicas (P4, P5, P8, P9, P10, P11, P12, P13, P14, P15, P19, P20, P32, P33, P34 e P35) e de Química (P1, P2, P3, P6, P7, P16, P17, P18, P21, P22, P29, P30 e P31).

Em relação aos conteúdos curriculares e temas transversais, das 35 situaçóes analisadas, podemos identificá-las como: situaçóes sobre questôes ambientais (P1, P2, P3, P4, P16, P17, P18, P34, P35), problemas tratando de química orgânica (P5, P6, P7, P31, P32), o corpo humano (P8, P9, P10, P11, P12, P13, P14, P15 P20, P28), produção de energia-ATP (P19), substâncias, misturas de substâncias e processos de separação de misturas (P21, P22), dopping esportivo (P23, P24, P25), alimentos (P26, P27), drogas composição, neurotransmissores, danos ao organismo (P29, P30, P31) e solo (P33).

Ao analisar a dicotomia entre dedutivo e náo dedutivo, que se referem ao tipo de raciocínio que o indivíduo deve acionar na resolução de um problema, podemos 
identificar que as 35 situaçóes apresentadas sáo do tipo indutiva e uma parte de um dos problemas (P24) pode ser parcialmente classificada como indutiva (porque é necessário utilizar apenas uma fórmula matemática para resolver a dada situação) e, parcialmente, do tipo dedutivo. Em relaçáo à dicotomia definido e indefinido, relativa à resoluçáo ou não do problema, identificamos que apenas $3 \%$ dos problemas podem ser classificados como tipo indefinido. Apenas o exemplar P7 foi um problema de difícil soluçáo.

Quanto às classificaçôes escolares, científicos ou problemas que levam em consideração as questóes do cotidiano, a maioria das 35 situações-problema foi classificada como problemas escolares (P4, P5, P6, P7; P8; P9, P10, P11, P12, P13, P14, P15, P16; P17; P18; P19, P21, P26, P27, P28, P30, P31, P32, P33), nenhuma como problema científico e a minoria como problemas do cotidiano (P1, P2, P3, P34, P35). Ainda podemos identificar outra categoria, que está relacionada aos conteúdos escolares e com as questôes do cotidiano (P20, P22, P23, P24 e P29).

As situações analisadas são, na maioria, problemas abertos, para os quais encontramos mais de uma resposta durante a resolução da situação. Os problemas $\mathrm{P} 7, \mathrm{P} 8$, P9, P10, P11, P12, P13, P14, P26, P31, P32 sấo classificados como problemas fechados.

Os professores elaboraram os problemas durante a formaçáo e apresentaram os problemas por escrito aos alunos, por isso foram classificados como formais. Os problemas tratados nesta análise são, na maioria, reais e não artificiais, pois, das 35 situaçóes elaboradas, 17 foram organizadas pensando na realidade do grupo em que esses problemas foram aplicados (P1, P2, P3, P9, P10, P11, P12, P13, P14, P15, P18, P20, P27; P29; P30; P31; P35). Os demais foram problemas artificiais, classificados de acordo com o conteúdo escolar da Série ou Ano em que foram utilizados.

Em relação à natureza dessas situaçóes-problema, podemos organizá-las de acordo com natureza teórica, experimental ou teórica-e-experimental. As questóes de natureza teórica são as que precisam de teorias que expliquem a sua resolução, enquanto que uma situação experimental precisa de dados empíricos para comprovar uma determinada solução de um problema. Já as de natureza teórica-e-experimental precisam tanto de dados empíricos quanto de conceitos para comprovar uma dada solução. Das 35 situaçóes apresentadas, a maioria é de natureza teórica, relacionada a algum experimento (P4, P5, P7, P21, P22, P28, P32; P33) e nenhuma de natureza puramente experimental.

A categorizaçáo dos problemas apresentada por Watts (1991) e outros autores permite que façamos uma análise das situaçóes elaboradas pelos professores em relação à escolha da natureza de cada problema. Das situaçóes-problema analisadas, podemos identificar que os professores têm preferência em formular problemas de linha teórica, ao passo que poucos têm habilidades para organizar situaçóes práticas ou teórico-práticas. Esse mesmo fato foi comprovado em outros cursos de formação organizados por nosso grupo de pesquisa (GOI; SANTOS, 2014). Isso parece indicar que os professores não demonstram intenção de elaborar problemas que possam ser utilizados no laboratório didático. Outro ponto a ser considerado relaciona-se à tendência dos professores em elaborar problemas de acordo com o conteúdo curricular, haja vista que nenhum propôs problemas náo-curriculares. Isso reforça o fato de os professores náo produzirem problemas científicos, o que demonstra sua preocupação em relação aos conteúdos curriculares apresentados nos planos de ensino e náo com a construção da própria ciência.

Os problemas elaborados pelos professores se constituíram, na maioria, em blocos sequenciais. Observa-se que apenas os problemas P19 e P20 foram construídos de forma 
unitária, ou seja, não estavam relacionados entre si (um trata do conteúdo de produção de energia-ATP e outro sobre as vacinas).

Além do fato de os problemas estarem organizados em blocos, devemos considerar que os professores em formação os produziram considerando que deveriam iniciar por situaçóes mais simples e, ao longo do processo, ir aumentando o grau de dificuldades conceituais. Isso é comprovado em várias situaçóes, como por exemplo nos problemas P21 e P22, em que se inicia a situação comentando sobre substância e misturas de substâncias, e no problema seguinte a situação é conduzida para os processos de separação de misturas. Observa-se que há um aumento das dificuldades apresentadas do P21 para o P22.

Outro exemplar que demonstra a gradação das dificuldades conceituais dos problemas está no P29 para o P30 e P31, que inicia contextualizando o tema "drogas", insere-se a questão da liberação dos neurotransmissores acionados pela ação das drogas no corpo humano, e solicita-se aos alunos a identificação de compostos orgânicos presentes nas drogas. Observa-se uma ampliação de dificuldades conceituais em cada uma das situaçóes-problema. Parece que os professores tiveram o cuidado de partir de situaçóes mais simples para as mais complexas e se preocuparam em criar situaçóes para o aluno elaborar suas hipóteses, descobrir a partir do seu próprio processo de busca (pesquisa), pois assim o estudante ganha autoconfiança e amplia o seu interesse pelo estudo da matéria.

Podemos dizer que o professor fez uso do referencial teórico trabalhado no curso de formação e elaborou os problemas valorizando os níveis de desenvolvimento dos estudantes. Bruner (1966, p.15) destaca que a aprendizagem escolar cria habilidades que mais tarde se transformam em atividades. Essas habilidades podem ser criadas a partir da resolução de situaçóes-problema, por isso os professores criaram possibilidades para um aprofundamento do saber em termos de ideias básicas e gerais, ou seja, os problemas foram organizados em blocos, pensando-se em um aprofundamento conceitual. Neste contexto, aprender Ciências é compreender as ideias fundamentais e reconhecer a utilidade e aplicabilidade de uma ideia a uma nova situaçáo e, assim, ampliar o conhecimento do educando.

Outro aspecto a ser considerado está relacionado ao fato de os professores terem organizado os problemas pensando em um currículo em espiral, levando em conta que podemos ensinar qualquer assunto em diferentes fases do desenvolvimento. Para Bruner (1966), o currículo deveria dar uma volta em torno de si mesmo, ou seja, os assuntos escolares deveriam ser estudados ao longo de anos, em níveis crescentes de complexidade, retornando a temas e conceitos já vistos e trabalhados.

Há muitas vantagens relacionadas ao uso da metodologia de RP na formação de professores. A investigação permitiu verificar que a metodologia se mostrou adequada para o tratamento dos conteúdos de Ciências, uma vez que o professor conseguiu assumir com mais autoria os momentos de planejamentos de sua própria aula, ou seja, foi ele quem criou situaçóes-problema. Quando o professor se propóe a formular problemas, deve pensar nas soluçóes propostas para a consequente resolução. Os problemas propostos não podem ter soluçóes óbvias, apresentar respostas diretamente no texto, nem dar pistas de sua resoluçáo no texto do problema (POZO, 1998).

Este pensar e criar situaçóes leva o professor a desencadear uma série de habilidades que envolvem o seu processo de formação. $\mathrm{O}$ professor-autor relaciona o pensamento 
sobre algo no mundo e o conhecimento sistematizado de Ciências. Pode pensar em uma estrutura didática que oriente o processo de construção do conhecimento de seus alunos.

\section{Consideraçóes finais}

Esta investigação confirma a importância e relevância de o professor ser autor de seu próprio material didático (NERY; MALDANER, 2012). Nesta perspectiva, o professor-autor é quem desenvolve o diálogo contextualizado nos problemas produzidos, é ele quem escolhe o conteúdo a ser trabalhado em cada situaçáo, a estrutura de desenvolvimento deste conteúdo, o grau de dificuldades conceituais abordados em cada situação e, principalmente, leva em consideração quem será o público que trabalhará com cada situação-problema, ou seja, o professor náo aborda conteúdos prontos de um livro didático, mas consegue produzir situaçóes relevantes com o contexto social de cada grupo escolar (GOI; SANTOS, 2014).

A experiência realizada e os dados obtidos indicaram que o desenvolvimento de competências no processo de elaboraçáo e resoluçáo de problemas pode ser realizado em curso de formação continuada que envolva professores da área de Ciências da Natureza. Privilegia-se a vivência da metodologia, superando a perspectiva de aprendizagem de uma técnica performática. Princípios como interdisciplinaridade, estudo extensivo, aprofundamento teórico, uso cotidiano da metodologia constituem-se como elementos formativos importantes a serem considerados em modelos de formaçáo de professores.

Os problemas elaborados pelos professores são qualificados e as análises indicaram que estes sáo coerentes com os fundamentos utilizados no curso de formaçáo. Há problemas bem construídos conceitualmente, organizados em uma sequência didática, com complexidade conceitual, com abordagem de temas transversais e que buscaram promover um trabalho interdisciplinar.

A partir deste trabalho, foi possível levantar características importantes da formação de professores para o desenvolvimento de habilidades para o uso da metodologia RP: I Articulaçáo entre universidade e escola, com o acompanhamento sistemático das açóes realizadas na Educação Básica; II- Estabelecimento de grupos de trabalho de professores, pois a organização de tempo e espaço para o trabalho coletivo foi determinante nessas 90 horas de curso, superando a visão individualista de formação docente; III- Professores como multiplicadores da metodologia.

O fortalecimento/pertencimento do grupo formaçáo faz esses professores se sentirem motivados e, em decorrência, disseminam a proposta para outros professores, até mesmo para outras áreas do conhecimento. Esse aspecto é relevante, pois o docente da Educação Básica, participante do processo formativo, atua como multiplicador de concepçôes teóricas, metodológicas e práticas em seus contextos de atuação. 
Referências

BRUNER, J. S. The process of Education. 10. imp. Harward University press Cambridge: 1966.

Uma nova teoria da aprendizagem. Rio de Janeiro: Bloch, 1969.

Sobre o Conhecimento: Ensaios de mãos esquerda. São Paulo: Phorte, 2008.

DEWEY, J. (1938). Experiência e Educação. Tradução de Renata Gaspar-Petrópolis, Rio de Janeiro: Vozes, 2010.

ECHEVERRÍA, M. D. P. P.; POZO, J.I. Aprender a resolver problemas e resolver problemas para aprender. In: POZO, J. I. (Org.). A solução de problemas: aprender a resolver, resolver para aprender. Porto Alegre: Artmed, 1998.

GIL-PÉREZ, D. New trends in science education. Int. J. SCI. EDUC, v.18, n. 8, p. 889-901, 1996.

GOI, M. E. J.; SANTOS, F.M.T. Formação de professores e o desenvolvimento de habilidades para a utilização da metodologia de resolução de problemas. Investigações em Ensino de Ciências (Online), v.19, p.431450, 2014.

LAUDAN, L. Progress and it's problems. Towards a Theory of Scientific Growth. London: Outledge \& Kegan Pau, 1977.275 p.

Science and relativism: some key controversies in the philosophy of science. Chicago: University of Chicago Press, 1990, 180 p.

MATTHEWS, M. R. Teaching the Philosophical and Worldview Dimension of Science. Science \& Education, v.18, n.6-7, p. 697-728, 2009.

NERY, B. K; MALDANER, O. A. Formação continuada de professores de química na elaboração escrita de suas aulas a partir de um problema. Revista Electrónica de Enseñanza de las Ciencias, v. 11, n.1, p.120144, 2012.

POZO, J. I. (Org.). A solução de problemas: aprender a resolver, resolver para aprender. Porto Alegre: Artmed, 1998.

POZO, J. I.; CRESPO, M. Á. G. A Solução de Problemas nas Ciências da Natureza. In: POZO, J. I. (Org.). A solução de problemas: aprender a resolver, resolver para aprender. Porto Alegre: Artmed, 1998.

WATTS, M. The Science of Problem-Solving - A Pratical Guide for Science Teachers. London: Cassell, 1991. 